\title{
Internet como herramienta en torno a la traducción al español de los productos turísticos alemanes
}

\author{
Cristina Martínez Fraile \\ Universidad de Sevilla \\ cmartinez@us.es \\ https://dx.doi.org/10.12795/futhark.2011.i06.08
}

\begin{abstract}
:
The tourism sector requires a language full of neologisms, foreign words, loans and other words of new acquisition. The dictionaries, including electronic ones, are unable to pick up a large number of concepts, which tends to disappear quickly because of the new trends of tourist travel. The main aim of our investigation is to resolve this problem, particularly when terms about "kinds of travel" have to be translated from German into Spanish. A chart with equivalences about Spanish and German tourism products is going to be showed to provide a systematic overview of the concepts translated. The terminology used by travel agencies and tour operators which appear in the network have been the main references for this investigation.
\end{abstract}

KEYwORDS: neologisms, dictionaries, tourism travel, network, translation

\section{RESUMEN:}

El sector turístico precisa de un lenguaje plagado de neologismos, extranjerismos, préstamos y otras palabras de nueva adquisición. La vertiginosa incorporación de nuevas voces supone un gran desafío para los diccionarios, incluso para los diccionarios electrónicos, incapaces de recoger todo un léxico de presencia efímera, pues un gran número de conceptos tiende a desaparecer con las modas. El problema se agudiza aún más cuando se trata de la traducción de términos alemanes al español, puesto que existen menos diccionarios en torno al tema. Nuestro artículo surge como respuesta ante la demanda de traducción del núcleo léxico formado por "los tipos de viaje". Con el fin de presentar una visión sistematizada de los conceptos traducidos mostraremos una tabla de equivalencias de productos turísticos alemanes y españoles. Para realizarla hemos tomado como referencia la terminología 
empleada por las agencias de viaje y otros operadores turísticos que aparecen en la red.

Palabras Clave: neologismos, diccionarios, viajes turísticos, internet, traducción

\section{INTRODUCCIÓN}

Los productos turísticos son ideales para ser expuestos en Internet y la red puede facilitar en gran medida la promoción y la distribución de los mismos a nivel mundial. Por esta razón, un gran número de páginas puede presentar una misma información en versión multilingüe. En este sentido su carácter "internacional" se convierte en uno de los rasgos distintivos de la actividad turística, hecho que genera una ingente cantidad de traducciones para las que, en muchas ocasiones, el traductor encuentra un vacío lexicográfico a la hora de traducir la inmensa multitud de neologismos que halla en un texto turístico, lo que le obliga a recurrir a textos paralelos y a equivalencias utilizadas en internet o en otros medios de comunicación. En su afán por ofrecer una traducción lo más fiel posible al original, tratará de encontrar el equilibrio en la tensión creada por respetar el texto de partida y por adaptarlo a la lengua meta. No pocas veces, tiene que arriesgarse con una traducción aproximada valiéndose de ciertas técnicas directas de traducción como el préstamo, el extranjerismo 0 el calco y de otras técnicas oblicuas como la transposición ${ }^{1}$. En definitiva, el traductor se siente responsable al tener que resolver el problema de los neologismos. Decimos bien cuando referimos que "se siente responsable" porque el texto turístico se utiliza como medio de promoción de productos y, en este sentido, las traducciones desacertadas utilizadas por las agencias 0 por los operadores turísticos pueden eclipsar la venta de verdaderos viajes de ensueño o dejar pasar excelentes gangas para el consumidor.

En este artículo nos disponemos a analizar un corpus de productos turísticos y/o tipos de viajes en alemán para hallar sus "posibles" equivalentes en español. Resaltamos que trataremos de ofrecer

${ }^{1}$ Veáse los distintos procedimientos de traducción aportados por VINAY \& DARBELNET, Stylistique comparée du français et de l'anglais. Méthode de traduction, Didier, Paris, 1958 y por NeWMARK, P., Manual de traducción. Madrid: Cátedra, 1992, págs. 99-129

Futhark 6 (2011)

Martínez, Internet como herramienta,

163-192

ISSN 1886-9300 
"posibles traducciones" porque la bibliografía con la que contamos en torno al tema es bastante escasa cuando se trabaja con un tecnolecto ${ }^{2}$ que va cambiando constantemente dependiendo de las modas, las tendencias y de la recepción y aceptación de los productos. Intentaremos cubrir, en la medida de lo posible, ese vacío lexicográfico presentando unas tablas que contienen un listado de productos turísticos en alemán y su traducción al español para lo que hemos tomado como referencia la fuente de información más actual e inmediata, internet. Hemos considerado como válida la terminología empleada por algunas agencias de viaje, tour operadores así como la información utilizada por otras organizaciones y empresas mayoristas y/o minoristas dedicadas al sector.

El hecho de tomar la lengua alemana como referencia para establecer este estudio contrastivo reside en el mismo impacto del turismo alemán en España. La afluencia de turistas alemanes en España es de tal magnitud que podría afirmarse que es el país de la Unión Europea desde donde procede el mayor número de turistas si nos basamos en el estudio sobre el turismo receptor propuesto por el Instituto Nacional de Estadística en los últimos cinco años ${ }^{3}$.

Turismo receptor. Entrada de visitantes. Serie 2001-2009 Entrada de turistas por país de residencia, indicador y periodo.

\footnotetext{
2 "La comunicación sobre temas científicos, así como sobre los tópicos y necesidades relacionadas con actividades laborales de orientación técnica se realiza con la ayuda de lenguajes técnicos, específicos para tratar la materia. Estos lenguajes se denominan tecnolectos. El tecnolecto se considera un subsistema de la respectiva lengua común. (...) En alemán, el tecnolecto en este ámbito coincide con lo que ellos denominan "Fachsprache." en el Máster Universitario en Traducción de textos con fines específicos,Interpretación y Doblaje de las lenguas española y alemana traducción al castellano de textos Biosanitarios, págs. 10 y 11.

${ }^{3}$ Página web del Instituto Nacional de Estadística (http://www.ine.es/). En su apartado de "Servicios" tiene como objetivo informar sobre los aspectos básicos del turismo y el transporte aéreo de pasajeros y mercancías. Las variables estudiadas son: turistas según procedencia y destino, ingresos de cada país procedentes del turismo, tráfico aéreo de pasajeros y mercancías.
}

Futhark 6 (2011)

Martínez, Internet como herramienta,

163-192

ISSN 1886-9300 
Unidades: número de turistas

\begin{tabular}{|c|c|c|c|c|c|}
\hline & \multicolumn{5}{|c|}{ Valor absoluto } \\
\hline & 2005 & 2006 & 2007 & 2008 & 2009 (1) \\
\hline Alemania & 9917619 & 10139582 & 10080606 & 10062629 & 8925908 \\
\hline Austria & 481852 & 525484 & 489482 & 546060 & 493834 \\
\hline Bélgica & 1821667 & 1820777 & 1724409 & 1636636 & 1596898 \\
\hline Dinamarca & 726899 & 806027 & 932132 & 956546 & 958910 \\
\hline Finlandia & 435747 & 473820 & 512922 & 509103 & 517503 \\
\hline Francia & 8874747 & 9081955 & 9004008 & 8149265 & 7916164 \\
\hline Grecia & 91291 & 84306 & 74119 & 82753 & 81596 \\
\hline Irlanda & 1365078 & 1508159 & 1630335 & 1658899 & 1458151 \\
\hline Italia & 2956891 & 3379001 & 3623091 & 3354251 & 3181559 \\
\hline Luxemburgo & 131276 & 123121 & 114945 & 133264 & 113176 \\
\hline Noruega & 786763 & 803061 & 861474 & 952720 & 887222 \\
\hline $\begin{array}{l}\text { Países } \\
\text { Bajos }\end{array}$ & 2434990 & 2549374 & 2503495 & 2479928 & 2094633 \\
\hline Portugal & 1991916 & 2195904 & 2414562 & 2224304 & 2051988 \\
\hline Reino Unido & 16090030 & 16210326 & 16296132 & 15775243 & 13324626 \\
\hline Rusia & 297794 & 341929 & 426688 & 509032 & 421161 \\
\hline Suecia & 916625 & 997998 & 1130057 & 1175260 & 975776 \\
\hline Suiza & 1155491 & 1377407 & 1376470 & 1286725 & 1141226 \\
\hline $\begin{array}{l}\text { Otros } \\
\text { Europa }\end{array}$ & 1713192 & 1894507 & 1731707 & 2019530 & 1800280 \\
\hline
\end{tabular}

2. LA IDIOSINCRASIA DEL TEXTO TURÍSTICO: UNA PUERTA DE ENTRADA PARA LOS NEOLOGISMOS.

El texto turístico presenta determinadas modalidades discursivas y una terminología propia pese a que "El léxico turístico asimila una 
terminología amplia procedente de diversos campos (geografía, economía, historia del arte, etc.). Balboni (1989: 56-57) describe la microlengua del turismo como un haz de microlenguas interrelacionadas, relativas a hotelería y restauración, transacciones comerciales, transportes, burocracia internacional, tiempo libre y espectáculos, historia y arte." ${ }^{4}$ De todo el entramado que envuelve al sector turístico, el núcleo léxico que aporta más incorporaciones es el específico que comprende aquellos términos técnicos relativos a los productos turísticos. Éste se conforma de un gran número de palabras de nueva creación, hecho que se explica por la aparición de nuevos productos turísticos, así como por el contacto de las distintas lenguas a la que está supeditada este sector. De este modo, el texto turístico se aleja de la política lingüística y proteccionista para con la lengua nacional mantenida por los organismos y las Academias de la lengua propias de cada país, como es el caso de la $\mathrm{RAE}^{5}$ en España, que rigen la incorporación a los diccionarios de las palabras nuevas. Su necesidad de adaptarse a las novedosas demandas del mercado turístico lo hace más vulnerable y por ello se llega a convertir en una puerta de entrada para numerosos neologismos. Este flujo de vocablos de nueva creación aparece inevitablemente por el mero trasvase de turistas de un país a otro. Así pues, la introducción de neologismos es una consecuencia directa de la oligosemia ${ }^{6}$ y estos llegan a ser la solución más inmediata para cubrir esta necesidad.

La vertiginosa avalancha de neologismos generados por el uso de internet, herramienta con la que más suelen trabajar los profesionales del sector turístico, supone un gran reto para los diccionarios, que trabajan a contratiempo. ${ }^{7}$ A pesar de todo, García Yebra advierte de la necesidad inminente de ocuparse a fondo de esta materia:

${ }^{4}$ CALVI, Ma VITTORIA, El léxico del turismo en http://www.ub.es/filhis/culturele/turismo.html

${ }^{5}$ La Real Academia de la Lengua se distinguía por el emblema "Limpia, fija y da esplendor". Precisamente "limpiar de extranjerismos" a la lengua española era una de sus principales tareas.

${ }^{6}$ Sobre todo en traducción se entiende como "los vacios semánticos existentes en un campo referencial determinado" en BUGNOT, MARIA-AGNE, Tesis Doctoral. Texto Turístico y Traducción especializada. Estudio crítico de un corpus español-francés sobre la Costa del Sol (1960- 2004) en MA Bugnot - dialnet.unirioja.es

7 Véase la importancia que empiezan a tener los términos de nueva adquisición procedentes de internet a los que Valentín Justel denomina "cyberismos" en su artículo Futhark 6 (2011)

Martínez, Internet como herramienta,

163-192

ISSN 1886-9300 
Hoy es mucho más importante cuantitativamente la traducción científica y técnica que la traducción literaria. (...). La presencia de términos especializados, accidental en textos literarios, es necesariamente habitual en escritos científicos o técnicos. Nadie puede traducir una obra de Medicina, de Física, de Matemáticas, de Arquitectura, sin conocer la terminología correspondiente. Redactar y publicar diccionarios o vocabularios de su propia especialidad debiera ser una de las ocupaciones primordiales de las Academias. Prestarían con ello un gran servicio al público lector en general, y sobre todo a los traductores $^{8}$

\subsection{LA TRADUCCIÓN DE LOS NEOLOGISMOS.}

Bajo la denominación de neologismos se encuentran tanto los términos de nueva creación como aquellas palabras preexistentes que adquieren un nuevo significado. En la mayoría de los casos no están lexicalizados y es por lo que "Los neologismos son probablemente el mayor problema con que se enfrentan el traductor no literario y el traductor profesional. Surgen continuamente objetos y procesos nuevos en tecnología y surge la necesidad de nombrarlos"

titulado "Neologismos, extranjerismos y cyberismos". Según V. Justel "la era de las nuevas tecnologías y las frecuentes migraciones sociales -motivadas por alcanzar un mayor nivel de bienestar, por causas políticas o por catástrofes humanitarias-, junto con un mayor dinamismo en las comunicaciones, están consiguiendo que lenguas que gozan de una tradición más que milenaria se transformen constantemente, a una velocidad mucho mayor que antes de la existencia de estos fenómenos, con nuevos matices de expresión procedentes de otros idiomas, que, en ocasiones, pueden enriquecer sus léxicos, pero que también pueden degradarlos. (...)Ahora bien, es el grado de utilización de los extranjerismos por una comunidad idiomática determinada lo que provoca su permanencia o desuso en la propia lengua, al margen del refrendo otorgado por instituciones como, en España, la RAE, cuya función esencial es la de limpiar, fijar y dar esplendor a la lengua de Cervantes." En http://www.cervantesvirtual.com/escaparate/neologismos.jsp

${ }^{8}$ García Yebra, V: Traducción, Academias y Terminología. En: Actas de la V JornadaColoquio de la Asociación Española de Terminología (AETER), "Comunicar y enseñar a comunicar el conocimiento especializado. Universidad de Alcalá, 15 de octubre de 2004. En http://cvc.cervantes.es/obref/aeter/conferencias/garcia.htm

${ }^{9}$ Ibid. NEWMARK, P. (1958).Pág. 193.

Futhark 6 (2011)

Martínez, Internet como herramienta,

163-192

ISSN 1886-9300 
Newmark determina la existencia de varios tipos de neologismos: palabras viejas con sentidos nuevos, palabras de nuevo cuño, palabras derivadas, abreviamientos, colocaciones, epónimos y seudoneologismos, entre otras ${ }^{10}$. De entre todos ellos, los que más abundan en este trabajo son las nuevas creaciones compuestas en alemán que traducidas al español presentan una forma muy distinta, pues en la mayoría de los casos los compuestos en alemán no se corresponden con un compuesto en español sino con una estructura en forma de sintagma preposicional.

Para incorporar las nuevas palabras, este lenguaje especializado en materia turística se vale de los mismos mecanismos de adquisición que cualquier lengua. Asimismo, no sólo habrá que adaptar las palabras desde el punto de vista del significante sino que se tendrá en cuenta tanto el significado como el componente cultural que contienen dichos conceptos. En cualquier caso, este componente cultural supone un obstáculo que el traductor ha de superar. Las vías de asimilación de una nueva terminología pueden ser muy variadas:

a) Es muy común utilizar una palabra preexistente en el léxico de una lengua para designar una nueva realidad. Esta técnica es una de las más aplicadas en la composición de las palabras alemanas. Asimismo, la composición se presenta como el recurso más productivo para esta lengua. Debido al carácter mismo del alemán, más sintético que la lengua española, se tiende a formar nuevas palabras con un significado muy preciso. Por ello en una palabra compuesta alemana se puede hallar suficiente información sobre un producto turístico sin tener que recurrir a una colocación ${ }^{11}$ o sintagma. Por el contrario, la lengua española, más analítica en comparación con la lengua alemana, en lo que a formación de palabras se refiere, recurre a sintagmas nominales compuestos de varias palabras que

\footnotetext{
10 lbíd. Págs. 193-207

${ }^{11}$ Cfr. en Alcaraz, E y MARTínez, Ma A., Diccionario de lingüística moderna. Barcelona: Ariel, 2004 (2..$^{a}$ ed.). La colocación designa aquellas combinaciones de unidades léxicas que por su uso frecuente son fijadas en la norma. Los paradigmas más utilizados en español son los señalados en el apartado c) del texto principal.
} 
informan bien sobre el lugar, la función, la actividad o el transporte.

A excepción de algunos extranjerismos como Camping, Caravaning, Safari o Trekking, el resto son palabras compuestas en el corpus alemán. En español también se introducen neologismos a partir de préstamos y extranjerismos aunque el procedimiento más recurrente es el de los sintagmas preposicionales como "viaje de aventuras", "viaje para niños", "viaje para la tercera edad" y las construcciones nominales más adjetivo. Esta última construcción se utiliza fundamentalmente en la traducción de composiciones con la extensión -tourismus, como por ejemplo "turismo urbano", "turismo cultural" o "turismo espacial". ${ }^{2}$

La mayoría de los compuestos que presenta el alemán en este trabajo no aparece en los diccionarios. No obstante, la formación de estos compuestos se ha realizado a partir de "palabras viejas", como las llama Newmark, que, en conjunción, dan lugar a un nuevo vocablo. Ej: Drogen + Tourismus > Drogentourismus; Kaffee + Fahrt > Kaffefahrt; Expedition + Reise $>$ Expeditionsreise.

b) La derivación es otro método muy productivo para la creación de neologismos aunque en nuestro trabajo carezca de presencia. Según Newmark "la inmensa mayoría de los neologismos son palabras que se derivan por analogía de morfemas del griego y del latín antiguo y tienen sufijos naturalizados de acuerdo con la lengua de llegada." ${ }^{13}$

c) La colocación es la técnica más empleada en las traducciones españolas, como ya hemos alusión anteriormente, pues se prefiere este tipo construcción a la composición. Las estructuras más comunes son las siguientes: nombre + nombre, nombre + preposición + nombre, verbo + preposición + sustantivo y la colocación nombre + adjetivo,.

d) En otras ocasiones se opta por el extranjerismo, por el calco o por el préstamo naturalizado cuando no se encuentra en

12 Véase la tabla.

${ }^{13}$ NeWMaRK, P. (1958). Pág. 197.

Futhark 6 (2011)

Martínez, Internet como herramienta,

$163-192$

ISSN 1886-9300 
la lengua receptora un término apropiado. Si se transfiere el término sin cambio alguno y se sigue manteniendo el significante original se habla de extranjerismo. En nuestro trabajo hemos encontrado algunos como Camping, Caravaning, Trekking y Safari, entre otros. Los tres primeros proceden del inglés y "Safari" del suajili. El inglés, como vehículo por excelencia en la comunicación internacional, está presente, según un estudio realizado por $\mathrm{Graddol}^{14}$, en doce campos principales internacionales y sitúa al turismo en el sexto puesto, de ahí que el inglés en esta lengua especializada desarrolle un papel primordial.

e) El calco semántico es otro procedimiento dentro de las técnicas de traducción directa y consiste en la imitación del término original en la medida que se traduce cada uno de sus lexemas. Ökotourismus/ecoturismo Ethnotourismus/etnoturismo son algunos ejemplos en nuestro estudio.

\section{CoRPus De EQUiVAlencias}

La mayoría de las denominaciones que hemos seleccionado aparecen como compuestos de Tourismus, Reise, Fahrt y Urlaub pero todas comparten el sema común de "viaje o producto turístico"15:

Abenteuerreise

Ethnotourismus

Weltraumtourismus

Autoreise

Butterfahrt

Kreuzfahrt

Busreise

Drogentourismus

Expeditionsreise

Forschungsreise

Frauenreise

Fahrrad-Urlaub

Kulturtourismus

Caravaning

Cluburlaub

Flugreise

Fernreise

Heliskiing

Individualreise

Fluss- Kreuzfahrt

Bahnreise

${ }^{14}$ GRADDOL, DAVID (1997:13). The future of English? A guide to forecasting the popularity of the English language in the 21st century. London: British Council. Available for free from the website of the British Council [1]. en http://www.britishcouncil.org/learning-elt-future.pdf

${ }^{15} \mathrm{La}$ selección de términos ha sido tomada de la siguiente dirección Übersicht Tourismus http://www.uni-protokolle.de/Lexikon/\%DCbersicht_Tourismus.html

Futhark 6 (2011)

Martínez, Internet como herramienta,

$163-192$

ISSN 1886-9300 


$\begin{array}{lll}\text { Geschäftsreise } & \text { Weltreise } & \text { Kurreise } \\ \text { Incentive Reise } & \text { Blaue Reise } & \text { Golfreise } \\ \text { Jacht-Reise } & \text { Jugendreisen } & \text { Badeferien } \\ \text { Langzeiturlaub } & \text { Naturismusurlaub } & \text { Camping } \\ \text { Reiterferien } & \text { Pilgerreise } & \text { Bildungsreise } \\ \text { Rundreise } & \text { Safari } & \text { Sextourismus } \\ \text { Segeltörn } & \text { Pauschalreise } & \text { Gruppenreise } \\ \text { Seniorenreise } & \text { Sportreise } & \text { Kinderreisen } \\ \text { Singlereise } & \text { Sprachreise } & \text { Kaffeefahrt } \\ \text { Städtereise } & \text { Ökotourismus } & \text { Trekking } \\ \text { Studienreise } & \text { Tauchreise } & \text { TourÜberwinterung } \\ \text { Surfreise } & \text { Survival Tour } & \text { Wallfahrt Urlaub } \\ \text { Therapeutisches Reisen } & \text { Wanderreise } & \text { Alkoholtourismus } \\ & \end{array}$

La traducción de estos términos del alemán al español parece no presentar muchos problemas al tratarse de compuestos en los que existe una relación semántica de identidad entre la unidad y sus componentes, esto es, el significado de estas palabras compuestas puede deducirse a partir de la traducción de sus miembros. La denominación de los conceptos viene determinada en función de la actividad, el transporte, el usuario o el lugar de destino. No obstante, muchos de ellos no aparecen recogidos en los diccionarios o léxicos especializados lo que, en ocasiones, provoca que no exista un consenso en lo que a denominación se refiere. Incluso dentro de una misma lengua puede haber diferencia entre los servicios que se ofrecen bajo una determinada denominación. Asimismo, es muy corriente que un mismo producto se presente con distinta denominación solapándose de este modo esos términos. En definitiva se trata más bien de opciones que quedan en manos de la oferta de las distintas agencias de viaje, quienes deciden incluir más o menos actividades bajo dicho término. Por este motivo, cuando las agencias de viaje emplean un término para denominar un producto incluyen a continuación todas las características que bajo esa denominación entienden. Véase los siguientes ejemplos:

Bajo la denominación "Viaje de aventuras" hay agencias que "sólo hablan de practicar "deportes de riesgo" mientras que otras agencias 
ofrecen otras alternativas como conocer "paisajes inéditos", "culturas indígenas", etc. En este sentido se aproxima mucho a los servicios que se ofrecen bajo los términos "Survival Tour" y "Expeditionsreise". ${ }^{16}$

Para otras denominaciones el procedimiento de la traducción de los lexemas de un compuesto "a modo de calco" o de "colocación" no es válido, puesto que la suma de los significados de sus lexemas no definen la palabra en su conjunto. Así sucede con Butterfahrt y Kaffeefahrt, cuya acuñación viene motivada por unas determinadas circunstancias: son neologismos creados in situ aunque luego su uso se ha extendido para denominar tipos de viaje con esas mismas características.

A continuación presentamos la tabla de equivalencias obtenidas así como la fuente directa de la que se han tomado los términos. Como ya hemos referido anteriormente, la escasez de referencias bibliográficas actualizadas en torno al tema (propio de este tecnolecto en continua transformación) nos ha obligado a dar por válida la terminología utilizada por determinadas agencias de viaje en la red. Por esta razón, ofrecemos, además de la dirección de internet, la contextualización del término en el discurso escrito.

Entendemos que no es necesario indicar la referencia bibliográfica de aquellos conceptos cuya traducción ha sido hallada en diccionarios tradicionales.

Como regla general sólo presentamos la tabla de equivalencias. En cambio, hemos considerado necesario definir algunos términos porque consideramos que, por lo novedoso del producto para el gran público, no basta con mostrar simplemente la equivalencia. Tal ha sido el caso de Heliskiing, Blaue Reise, Butterfahrt y Kaffeefahrt, entre otras.

\begin{tabular}{|l|l|}
\hline TÉRMINO ALEMÁN & EQUIVALENTE ESPAÑOL \\
\hline
\end{tabular}

${ }^{16}$ Consúltese la tabla. 


\begin{tabular}{|c|c|}
\hline $\begin{array}{l}\text { Abenteuerreise } \\
\text { (Se incluye no sólo la práctica de deportes de } \\
\text { riesgo sino también expediciones a lugares } \\
\text { inéditos) }\end{array}$ & $\begin{array}{l}\text { viaje de aventuras } \\
\text { Te ofrecemos viajes de aventura en estado } \\
\text { puro, (...) en http://www.pasonoroeste.com/ } \\
\text { viajes de aventura con Viajes Tuareg. } \\
\text { Viajes y expediciones a destinos inéditos o } \\
\text { culturalmente diferentes. Viajes en grupo } \\
\text { reducido y viajes a medida para ... } \\
\text { www.tuaregviatges.es/ }\end{array}$ \\
\hline $\begin{array}{l}\text { Alkoholtourismus } \\
\text { Der Alkoholtourismus ist eine besondere } \\
\text { Form des Tourismus, der aufgrund der } \\
\text { Prohibition von Alkohol oder auch wegen der } \\
\text { Preisunterschiede für alkoholische Getränke } \\
\text { in verschiedenen Ländern entstanden ist. } \\
\text { http://www.suchtmittel.de/info/alkohol/000604. } \\
\text { php }\end{array}$ & 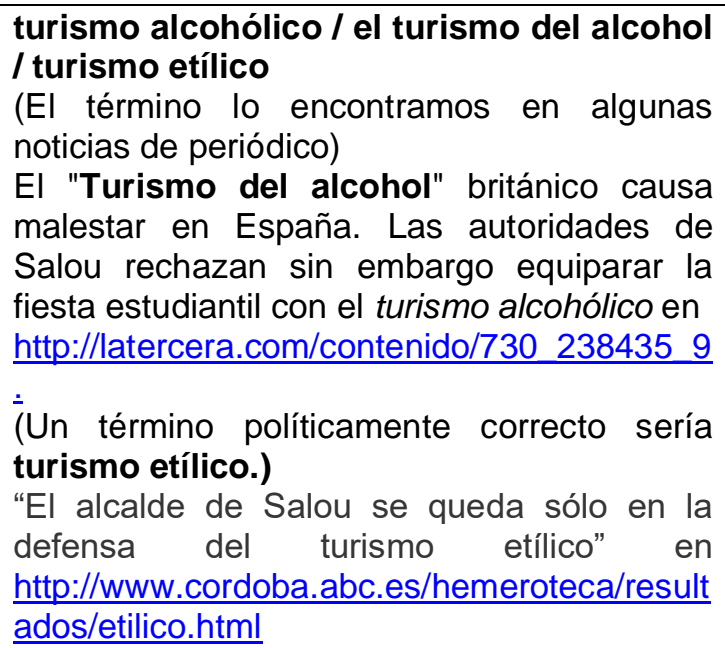 \\
\hline Autoreise & $\begin{array}{l}\text { viaje en coche } \\
\text { http://dict.leo.org }\end{array}$ \\
\hline $\begin{array}{l}\text { Badeferien } \\
\text { Mit der Reisesuchmaschine können Sie } \\
\text { unzählige Pauschalreisen an diesen und } \\
\text { weiteren Badeferiendestinationen vergleichen }\end{array}$ & $\begin{array}{l}\text { vacaciones en la playa } \\
\text { vacaciones de sol y playa } \\
\text { vacaciones en la playa, hoteles en la playa, } \\
\text { golf en la playa, deportes náuticos. }\end{array}$ \\
\hline
\end{tabular}

17 Deducimos el término a partir de algunas páginas que ofrecen estos destinos turísticos y que siempre son playas. Para constatarlo hemos consultado también la traducción del alemán al inglés y su equivalencia es: sun holidays. La traducción del término "sun holidays" al español es "vacaciones de sol" o "vacaciones de sol y playa" 


\begin{tabular}{|c|c|}
\hline $\begin{array}{l}\text { und danach direkt beim Veranstalter buchen: } \\
\text { http://www.reisen.ch/badeferien// } \\
\text { seaside tourism http://dict.leo.org/ }\end{array}$ & wwW. vacacionesenlaplaya \\
\hline Bahnreise & $\begin{array}{l}\text { viaje en tren } \\
\text { http://dix.osola.com/index.php }\end{array}$ \\
\hline Bildungsreise & $\begin{array}{l}\text { viaje educativo } \\
\text { http://dict.leo.org } \\
1 . \quad \text { Qué es un viaje educativo? } \\
\text { No existe una definición exacta de lo que es } \\
\text { un viaje educativo, pero intentaremos } \\
\text { especificar, mediante una explicación } \\
\text { secuencial, su significado } \\
\text { www.capitannemo.com.ar/que\%20es\%20un } \\
\text { \%20viaje\%20educativo.htm }\end{array}$ \\
\hline Blaue Reise & $\begin{array}{l}\text { viaje azul }{ }^{18} \\
\text { http://www.isyayachting.com/es/ }\end{array}$ \\
\hline Busreise & viaje en autobús \\
\hline $\begin{array}{l}\text { Butterfahrt }{ }^{19} \\
\text { Eine Butterfahrt war ursprünglich (seit } \\
\text { ca.1970) eine Einkaufsfahrt auf einem } \\
\text { Ausflugsschiff, die über die auf See gelegene } \\
\text { Zollgrenze von Deutschland hinausführte. } \\
\text { Dies ermöglichte es, innerhalb der Grenzen } \\
\text { der Zollbestimmungen zahlreiche Artikel } \\
\text { billiger einzukaufen, als sie in Deutschland } \\
\text { erhältlich waren. Dazu gehörte vor allem die } \\
\text { in Dänemark damals weit preiswertere Butter, }\end{array}$ & (No se conoce traducción alguna) \\
\hline
\end{tabular}

${ }^{18}$ El viaje azul es un trip velero en un barquito tradicional de madera y con velas a lo largo de la costa egea y mediterránea de Turquía y Grecia.

19 Se trata de un término adquirido en unas circunstancias espacio-temporales determinadas como fue el primer viaje en barco hacia Dinamarca en busca de la preciada mantequilla. Se trataba de un viaje que permitía comprar productos más baratos que en Alemania.

En España puede compararse con los viajes realizados a Gibraltar, a Andorra y a Portugal donde es posible comprar más productos más baratos o libres de impuestos.

Sin embargo, no hemos hallado ni en la red la acepción "viajes dutyfree", solamente el término "tiendas dutyfree" en http://de.wikipedia.org/wiki/Butterfahrt

Futhark 6 (2011)

Martínez, Internet como herramienta,

$163-192$

ISSN 1886-9300 


\begin{tabular}{|c|c|}
\hline $\begin{array}{l}\text { von der diese Unternehmungen den Namen } \\
\text { erhielten } \\
\text { http://de.wikipedia.org/wiki/Butterfahrt }\end{array}$ & \\
\hline Camping & camping \\
\hline Caravaning & $\begin{array}{l}\text { caravaning } \\
\text { Salón internacional de Caravaning } \\
\text { http://www.saloncaravaning.com/ }\end{array}$ \\
\hline $\begin{array}{l}\text { Cluburlaub } \\
1 . \quad \text { Cluburlaub buchen } \mid \text { Urlaub all- } \\
\text { inclusive | Club Hotel Clubschiff ... } \\
\text { Freizeitreisen präsentiert Cluburlaub / } \\
\text { Kreuzfahrt / Urlaub im Klub, Ferienhaus - } \\
\text { direkte sofortige } \\
\text { www.cluburlaub.com/ } \\
\text { (En alemán encontramos una definición en la } \\
\text { red: } \\
\text { Als Cluburlaub wird eine besondere Form } \\
\text { von Urlaub bezeichnet, in der sich die } \\
\text { Urlauber überwiegend in einer räumlich von } \\
\text { der Umgebung abgetrennten Ferienanlage } \\
\text { aufhalten. In der Regel wird der gesamte } \\
\text { Tagesablauf der Clubgäste durch spezielle } \\
\text { Freizeitangebote bestimmt. Für die } \\
\text { Unterhaltung der Gäste sorgen dabei so } \\
\text { genannte Animateure. In der Regel gibt es } \\
\text { Sport, Fitness, Wellness, Hobbykurse, } \\
\text { Unterhaltung, Kinderbetreuung. Sogenannte } \\
\text { Abendshows gestalten die Animateure mit } \\
\text { Gesang, Sketchen, Quiz usw. }\end{array}$ & $\begin{array}{l}\text { club de vacaciones } \\
1 . \quad \text { Spanair cerrará el turoperador Club } \\
\text { de Vacaciones en septiembre ... } \\
\text { 30 Abr } 2010 \text {.... El grupo Spanair cerrará el } \\
\text { touroperador Club de Vacaciones en } \\
\text { septiembre } \\
\text { wWw.elpais.com/articulo/.../Club/Vacaciones } \\
\text { /...13/Tes - }\end{array}$ \\
\hline
\end{tabular}

20 Realmente se trata de un término aplicado más bien a los hoteles y su forma de gestionar unas vacaciones (con programación de animación, deportes, espectáculos y otras alternativas más para sus clientes) que a un tipo de vacaciones como sugiere el término en alemán.

Así se presentan algunos hoteles como Hotel Club Playa Blanca, Club de Vacaciones Torrequebrada, etc. Por ello, a partir de una traducción directa que hemos seleccionado de varias páginas, pensamos que se trata de un tour operador. 


\begin{tabular}{|c|c|}
\hline \multicolumn{2}{|l|}{ http://de.wikipedia.org/wiki/Cluburlaub } \\
\hline Drogentourismus & $\begin{array}{l}\text { turismo de las drogas / turismo de la } \\
\text { droga } \\
\text { Holanda se plantea terminar con el "turismo } \\
\text { de las drogas "http://www.libertaddigital.com } \\
1 . \quad \text { Turismo de drogas | HuumeBoikotti } \\
\text { En muchos países, además de la cultura, el } \\
\text { paisaje o la comida exótica, los turistas están } \\
\text { en las posibilidades de consumir drogas } \\
\text { www.huumeboikotti.org/es/turismo.html }\end{array}$ \\
\hline \multirow[t]{2}{*}{ Ethnotourismus } & $\begin{array}{l}\text { etnoturismo / turismo étnico o turismo de } \\
\text { las etnias. }{ }^{21}\end{array}$ \\
\hline & $\begin{array}{l}\text { http://www.boletin- } \\
\text { turistico.com/diccionario.html?task=list\&g } \\
\text { lossid=1\&letter=E\&page }=6\end{array}$ \\
\hline Expeditionsreise & $\begin{array}{l}\text { viaje de expedición } \\
1 . \quad \text { Rutas / Excursiones Viajes de } \\
\text { Expedicion de Compañía de Guías de ... } \\
\text { Rutas / Excursiones Viajes de Expedición } \\
\text { producto o servicio que pertenece al catálogo } \\
\text { de productos de la empresa Compañía de } \\
\text { Guías de Patagonia en ... } \\
\text { argentina.acambiode.com } \\
\text { Viajes a Expediciones } \\
\text { http://www.trekkingyaventura.com/expedicion } \\
\text { es/index.htm }\end{array}$ \\
\hline $\begin{array}{l}\text { Fahrrad-Urlaub } \\
\text { (Este anuncio en la red ofrece una imagen }\end{array}$ & $\begin{array}{l}\text { vacaciones para ciclistas } \\
\text { Vacaciones para ciclistas en Europa }\end{array}$ \\
\hline
\end{tabular}

${ }^{21}$ En Colombia, " Es el turismo especializado y dirigido que se realiza en territorios de los grupos étnicos con fines culturales, educativos, y recreativos que permite conocer los valores culturales, forma de vida, manejo ambiental, costumbres de los grupos étnicos así como los aspectos de su historia." (LEY 300.96)

${ }^{22}$ Simplemente también puede encontrarse traducido como "expedición". Bajo este término se entiende que se incluye la extensión "viaje".

Futhark 6 (2011)

Martínez, Internet como herramienta,

163-192

ISSN 1886-9300 


\begin{tabular}{|c|c|}
\hline 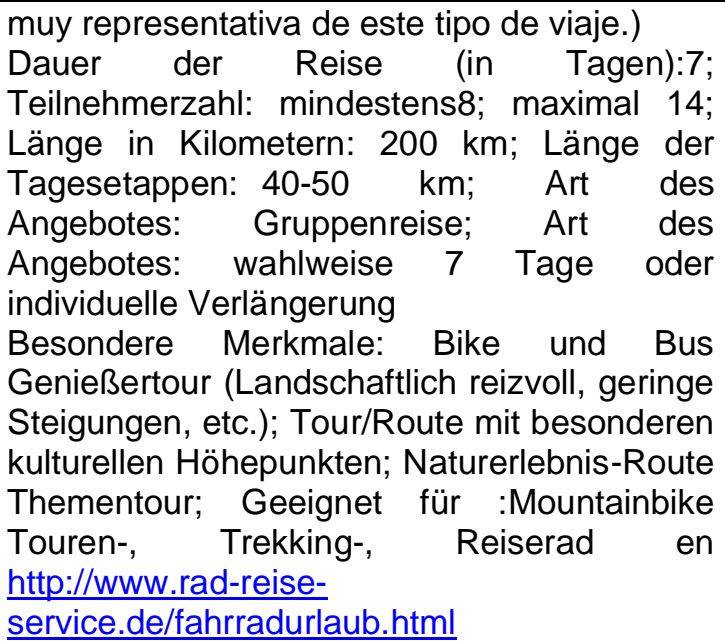 & $\begin{array}{l}\text { Según los expertos de Guardian Travel, } \\
\text { estos son los } 10 \text { mejores lugares en Europa } \\
\text { para pasar unas vacaciones haciendo } \\
\text { ciclismo. } \\
\text { http://viajar.euroresidentes.com/2008/08/vac } \\
\text { aciones-para-ciclistas-en-europa.html }\end{array}$ \\
\hline 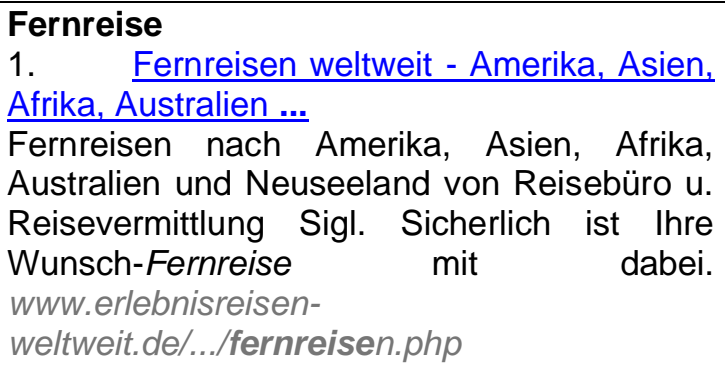 & viaje de larga distancia ${ }^{23}$ \\
\hline Flugreise & viaje en avión \\
\hline Fluss-Kreuzfahrt & $\begin{array}{l}\text { cruceros fluviales } \\
\text { El especialista en cruceros } \\
\text { Conoce los ríos del mundo } \\
\text { http://www.crucerosfluviales.es/ }\end{array}$ \\
\hline Forschungsreise & viaje de investigación / científico \\
\hline
\end{tabular}

${ }^{23}$ Primero hacemos una traducción al inglés y de esta al español: ing. long-haul journey > esp. viaje de larga distancia. Por la oferta que se hace, parece que se trata de viajes a otros continentes.

Futhark 6 (2011)

Martínez, Internet como herramienta,

$163-192$

ISSN 1886-9300 


\begin{tabular}{|c|c|}
\hline & $\begin{array}{l}\text { 1. Los Viajes de Exploración Científica - } \\
\text { UCA.es Universidad de Cádiz } \\
\text { La época de las grandes expediciones } \\
\text { marítimas, que iniciaron los viajes científicos } \\
\text { del siglo XVIII con personajes como Charles } \\
\text { de la Condamine (1735), ... } \\
\text { www.uca.es/web/organizacion/.../fondos_bib } \\
6 \text { - }\end{array}$ \\
\hline 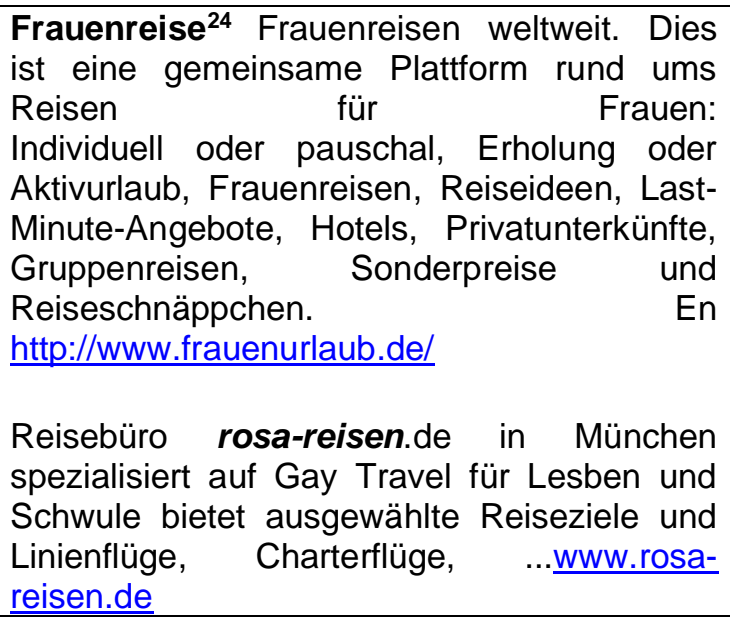 & $\begin{array}{l}\text { viajes para mujeres } \\
\text { Una ruta exclusiva de } 14 \text { días solo para } \\
\text { mujeres, desde el Japón más moderno hasta } \\
\text { la cultura tradicional. } \\
\text { http://rutasmagicas.es/viajes-para-mujeres- } 1 /\end{array}$ \\
\hline Geschäftsreise & viaje de negocios \\
\hline Golfreise & $\begin{array}{l}\text { viaje de golf } \\
\text { Bienvenido a www.elrincondelgolf.es. Aquí } \\
\text { encontrarás los mejores viajes de } \\
\text { golf, torneos, campos de golf, y las mejores }\end{array}$ \\
\hline
\end{tabular}

${ }^{24}$ Por ejemplo esta página tiene contenido lésbico. Buscamos también en alemán una
agencia que contenga la extensión "rosa" y de nuevo encontramos páginas para
homosexuales
${ }^{25}$ Otro término que hemos encontrado ha sido los " Viajes en Rosa" (véase en la nota a pie
anterior las connotaciones de este concepto). Son viajes estudiados para señoras solas y
solteras.
Se trata de propuestas destinadas solo a un público femenino en las que se unen relax,
aventura, cultura, aventura, deporte, un pellizco de misterio y alguna sorpresa. En
http://www.hotelbienestar.com/es-es/mujeres-solas.htm
Futhark 6 (2011) Martínez, Internet como herramienta,

163-192

ISSN 1886-9300 


\begin{tabular}{|c|c|}
\hline & $\begin{array}{l}\text { propuestas para realizar tus vacaciones, (...) } \\
\text { en www.elrincondelgolf.es/epages/ea3754 }\end{array}$ \\
\hline Gruppenreise & viaje en grupo \\
\hline Heliskiing & $\begin{array}{l}\text { heliesqui }{ }^{26} \\
\text { http://www.termcat.cat/dicci/hivern/index.html }\end{array}$ \\
\hline Incentive Reise & viaje de incentivos \\
\hline Individualreise & viaje individual ${ }^{27}$ en http://en.wikipedia.org \\
\hline Jacht-Reise & viaje en yate \\
\hline Jugendreisen & $\begin{array}{l}\text { viaje juvenil } \\
\text { http://conjuge.blogspot.com/2010/01/ en } \\
\text { viaje para jóvenes en } \\
\text { http://www.viajesybilletesdeavión.es/online- } \\
\text { viajes-para-jovenes-html }\end{array}$ \\
\hline $\begin{array}{l}\text { Kaffeefahrt } \\
\text { Eine Kaffeefahrt ist die verschleiernde } \\
\text { Bezeichnung für eine organisierte Fahrt mit } \\
\text { dem Bus oder Schiff mit angeschlossener } \\
\text { Verkaufsveranstaltung. Teilnehmer sind } \\
\text { typischerweise Rentner, die das Angebot } \\
\text { einer scheinbar billigen Ausflugsfahrt mit } \\
\text { Kaffee-und-Kuchen (daher der Name) oder } \\
\text { einem Mittagessen nutzen. } \\
\text { http://de.wikipedia.org/wiki/Kaffeefahrt }\end{array}$ & $\begin{array}{l}\text { turismo } \\
\text { http://www.viajeshobby.com/quienes somos. } \\
\mathrm{htm}\end{array}$ \\
\hline Kinderreisen & $\begin{array}{l}\text { viaje para niños / turismo infantil } \\
\text { Además, a partir de abril } \\
\text { inaugura ubyviajes.com } \\
\text { una agencia }\end{array}$ \\
\hline
\end{tabular}

${ }^{26}$ Se trata de esquí alpino fuera de la pista. Se accede a la zona por un helicóptero y no por un telesquí

${ }^{27}$ No hay que confundirlo con el "Singlereise".

El turismo individual es aquel cuyo programa de actividades e itinerario son decididos por los viajeros sin intervención de operadores turísticos.

${ }^{28}$ Es el término que más se aproxima. Mediante este tipo de turismo se ofrece la posibilidad de realizar campañas de marketing ofreciendo regalos a sus clientes. El regalo ofrecido a sus clientes siempre estará relacionado directamente con los viajes, tanto de ocio como de negocios. 


\begin{tabular}{|c|c|}
\hline & $\begin{array}{l}\text { especializada en turismo infantil, con } \\
\text { planificación específica e información para } \\
\text { viajes con niños, campamentos, colonias o } \\
\text { granjas-escuelas } \\
\text { http://www.bebesymas.com/noticias/babyviaj } \\
\text { es-agencia-de-viajes-para-ninos }\end{array}$ \\
\hline Kreuzfahrt & crucero \\
\hline Kulturtourismus & turismo cultural \\
\hline $\begin{array}{l}\text { Kurreisen } \\
\text { (bajo esta página se encuentran viajes de } \\
\text { tratamiento y belleza) }\end{array}$ & $\begin{array}{l}\text { viaje de salud y bienestar en } \\
\text { viajesdestinos.com/viaje-de-salud-y- } \\
\text { bienestar-en-castilla-la-mancha/ } \\
\text { viaje de tratamiento y belleza } \\
\text { viaje curativo }^{30}\end{array}$ \\
\hline Langzeiturlaub & $\begin{array}{l}\text { vacaciones de larga duración } \\
\text { 1. Aparcamiento Aeropuerto Barcelona } \\
-\quad . . \text { Aparcamiento Aeropuerto ... larga } \\
\text { estancia Barcelona, Aeropuerto de } \\
\text { Barcelona. más info Larga Estancia Viajes o } \\
\text { vacaciones de larga duración (...) } \\
\text { www.largaestancia }\end{array}$ \\
\hline Naturismusurlaub & $\begin{array}{l}\text { naturismo / nudismo } \\
\text { vacaciones nudistas / naturistas } \\
1 . \quad \text { Vacaciones nudistas : Foro } \\
\text { enFemenino } \\
\text { foro.enfemenino.com/.../_f7109_voyages1- } \\
\text { Vacaciones-nudistas.html } \\
\text { naturistas en total armonía } \\
\text { Www.educared.net/.../hemero/.../naturismo }\end{array}$ \\
\hline Ökotourismus & ecoturismo \\
\hline Pauschalreise & viaje con todo incluido \\
\hline Pilgerreise & $\begin{array}{l}\text { viaje de peregrinación / peregrinación / } \\
\text { peregrinaje }\end{array}$ \\
\hline
\end{tabular}

${ }^{29}$ Esta traducción es la que más se ajusta a los viajes ofrecidos bajo Kurreisen

${ }^{30}$ El tipo de viaje curativo ofrecido en la red no coincide con los ofertados bajo la denominación Kurreisen 


\begin{tabular}{|c|c|}
\hline & $\begin{array}{l}\text { http://dict.leo.org } \\
\text { http://www.turismoyperegrinaciones.com }\end{array}$ \\
\hline $\begin{array}{l}\text { 1. } \quad \text { Reiterferien } \\
\text { 2. } \quad \text { Reiterferien, Reiturlaub, Reiterurlaub, } \\
\text { Reitferien, Reiterreisen ... } \\
\text { Hier finden Sie die besten Angebote zum } \\
\text { Thema Reiterferien, Reiturlaub, Reiterreisen, } \\
\text { Reitferien, } \\
\text { www.reiten.de/urlaubundfreizeit.html - }\end{array}$ & $\begin{array}{l}\text { vacaciones a caballo } \\
\text { Vacaciones-a-caballo.com - índice de } \\
\text { vacaciones de jinete y ... Vacaciones a } \\
\text { caballo, de jinete y equitación de recreo, } \\
\text { hípica de tiempo libre para adultos, niños/as } \\
\text { www.vacaciones-a-caballo.com/ }\end{array}$ \\
\hline Rundreise & $\begin{array}{l}\text { gira / tour / circuito } \\
\text { Circuito por Alemania - Viajes Alemania } \\
\text { Viaje a Alemania. } 8 \text { días de viaje, incluyendo: } \\
3 \text { noches en Berlín, } 2 \text { en Hamburgo, } 1 \text { en } \\
\text { Colonia y } 1 \text { en Frankfurt. } \\
\text { http://destinia.com/viajes/Circuito-por- } \\
\text { Alemania---Viajes-Alemania }\end{array}$ \\
\hline Safari & safari \\
\hline Segeltörn & $\begin{array}{l}\text { viaje en velero } \\
\text { http://dict.leo.org } \\
\text { viaje de barco de vela } \\
\text { Los yates o barcos a vela nos permiten } \\
\text { disfrutar de la manera más natural de } \\
\text { navegar. Se pueden hacer paseos de un día } \\
\text { o de varios días. En general son grupos } \\
\text { reducidos, aunque puede alcanzar las } 200 \\
\text { personas incluyendo la tripulación. } \\
\text { http://locuraviajes.com/blog/viajar-en-barco- } \\
\text { consejos/ }\end{array}$ \\
\hline Seniorenreise & $\begin{array}{l}\text { viajes para personas mayores } \\
\text { viajes para la Tercera Edad } \\
\text { wwW. tercera-edad.org/.../vacaciones- } \\
\text { imserso.asp } \\
\text { http://dict.leo.org } \\
\text { viajes de pensionistas }\end{array}$ \\
\hline Sextourismus & $\begin{array}{l}\text { turismo sexual } \\
\text { El turismo sexual es una forma de turismo } \\
\text { con el propósito de sostener relaciones }\end{array}$ \\
\hline
\end{tabular}

Futhark 6 (2011)

Martínez, Internet como herramienta,

163-192

ISSN 1886-9300 


\begin{tabular}{|c|c|}
\hline & $\begin{array}{l}\text { sexuales, normalmente con prostitutas pero } \\
\text { también puede darse que mujeres busquen } \\
\text { oportunidades sexuales con hombres o con } \\
\text { mujeres e incluso entre personas del mismo } \\
\text { sexo. En Thesaurus of the International } \\
\text { Center for Research and Study on Tourism } \\
\text { (EN>FR).http://www.cirettourism.com/index/t } \\
\text { hesaurus_stu.html\#S } \\
\text { http://es.wikipedia.org/wiki/ }\end{array}$ \\
\hline Singlereise & $\begin{array}{l}\text { viajes para singles / viajes para solteros } \\
1 . \quad \text { VIAJARSOLO Viajes para Singles } \\
\text { SOLTEROS VIAJES con otros Solteros ... } \\
\text { VIAJARSOLO Viajes y vacaciones } \\
\text { compartiendo emociones con otros singles, } \\
\text { actividades para solteros o familias } \\
\text { monoparentales. } \\
\text { http://www.viajarsolo.com/ }\end{array}$ \\
\hline Sportreise & $\begin{array}{l}\text { viajes de deporte / vacaciones deportivas } \\
\text { viajes } \begin{array}{c}\text { deportivos } \\
\text { / }\end{array} \\
\text { http://www.esports } 10 . c o m / \text { esp/index.php }\end{array}$ \\
\hline $\begin{array}{l}\text { Sprachreisen } \\
\text { http://www.sprachreise.com/ }\end{array}$ & $\begin{array}{l}\text { viaje de idiomas } \\
\text { Elige entre los diferentes viajes de idiomas } \\
\text { que te ofrece EF } \text { Education First,... }\end{array}$ \\
\hline
\end{tabular}

${ }^{31}$ Tienen como objetivo practicar deportes. También podrían incluirse bajo esta denominación aquellos que tienen como meta ser espectadores de algún evento deportivo: un premio, una competición, una final, etc. En este caso la búsqueda sería por viajes a eventos deportivos o por turismo deportivo

Futhark 6 (2011)

Martínez, Internet como herramienta,

163-192

ISSN 1886-9300 


\begin{tabular}{|c|c|}
\hline & $\frac{\text { http://www.ef.com/info/es/viajes-de- }}{\text { idiomas.html?tr=HQ\&tc=HQ }}$ \\
\hline $\begin{array}{l}\text { Städtreise } \\
\text { http://www.stern.de/reise/europa/staedtreise- } \\
\text { sevilla-fruehstart-in-den-fruehling- } \\
1536571 . \mathrm{html}\end{array}$ & $\begin{array}{l}\text { turismo urbano } \\
\text { El día de hoy hemos decidido practicar } \\
\text { turismo urbano y cultural en Europa... } \\
\text { http://www.viajesyturistas.com/turismo- } \\
\text { urbano-en-europa }\end{array}$ \\
\hline Studienreise / Bildungsreise & viaje de estudios, viaje de formación \\
\hline Surfreise & $\begin{array}{l}\text { viaje de surf / viajes surf } \\
1 . \quad \text { Viajaysurfea - Central de reservas ... } \\
\text { Surfea los mejores destinos ... } \\
\text { Conciertos Viajes } \\
\text { www. viajaysurfea.com/ } \\
1 . \quad \text { Viajes Surf Limit - Previsiones de } \\
\text { olas en todo el mundo } \\
\text { Viajes surflimit, destinos a Maldivas, Brasil, } \\
\text { mentawai, mauricio, indonesia, bali, costa } \\
\text { rica, mexico, viajes de surf, escuelas de surf. } \\
\text { www.surfdestiny.com }\end{array}$ \\
\hline Survival Tour & $\begin{array}{l}\text { tour de supervivencia } \\
\text { ing. survival > esp. supervivencia } \\
1 . \quad \text { TOURS ESPECIALES - Agência } \\
\text { Orquídea Amazônica - Amazon Tours ... } \\
\text { Haga con nosotros un tour de supervivencia } \\
\text { bajo las instrucciones de un conocedor y } \\
\text { descubra los recursos naturales de la selva y } \\
\text { las estrategias indígenas } \\
\text { www.orquideatours.com/specialtours }\end{array}$ \\
\hline Tauchreise & $\begin{array}{l}\text { viaje de buceo } \\
1 . \quad \text { Viajes Iberia - Sección Especial - } \\
\text { Abando Dive } \\
\text { Ya tenemos disponible en cualquier oficina } \\
\text { Viajes lberia el catálogo de esta temporada } \\
\text { de Viajes de Buceo con la garantía de } \\
\text { Abando Dive Travel y de venta } \\
\text { www.viajesiberia.com/.../subhomeBuceo.as } \\
\text { px }\end{array}$ \\
\hline
\end{tabular}




\begin{tabular}{|c|c|}
\hline Therapeutisches Reisen & viaje terapéutico \\
\hline $\begin{array}{l}\text { TourÜberwinterung } \\
\text { 12. bis } 61 . \text { Tag'.00 } \\
\text { Überwintern Sie auf dem modernen } \\
\text { Campingplatz } \quad \text { "Atlantica Parc"! } \\
\text { Den nasskalten Winter in Deutschland } \\
\text { vergessen Sie schnell bei dem milden Klima } \\
\text { in der Bucht von Agadir... en http://www.ibea- } \\
\text { tours.de/marokko-ueberwintern.htm }\end{array}$ & (No se conoce traducción) \\
\hline Trekking & $\begin{array}{l}\text { senderismo, Trekking } \\
\text { (se recogen los dos términos) } \\
1 . \quad \text { Viajes Trekking \& Aventura } \\
\text { Agencia de viajes especializada en } \\
\text { organizacion de viajes de aventura, trekking } \\
\text { y expediciones a los lugares y destinos mas } \\
\text { remotos del planeta para grupos ... } \\
\text { www.trekkingyaventura.com/ } \\
\text { trekking: actividad que consiste en realizar } \\
\text { una excursión a pie por senderos, caminos y } \\
\text { veredas. } \\
\text { Sinónimo(s): Senderismo } \\
\text { http://www.poraqui.net/diccionario/index.php/t } \\
\text { erm/Glosario+de+turismo+y+hosteler\%C3\% } \\
\text { ADa,trekking.xhtml }\end{array}$ \\
\hline Wallfahrt Urlaub & $\begin{array}{l}\text { peregrinaciones } \\
\text { También existe el término Pilgerreise. }\end{array}$ \\
\hline Wanderreise & $\begin{array}{l}\text { viaje de senderismo } \\
1 . \quad \text { Viajes de Aventura } \\
\text { www.turingactiva.com Los mejores viajes } \\
\text { de Senderismo y aventura internacionales. } \\
\text { El término inglés trekking también hace } \\
\text { referencia a "viaje de senderismo". }\end{array}$ \\
\hline
\end{tabular}

${ }^{32}$ Tour de hibernación sería la traducción más adecuada, puesto que los viajes ofertados en páginas alemanas aluden precisamente a periodos largos de vacaciones en lugares templados para evitar el mal tiempo invernal alemán. No obstante, no aparece como tipo de viaje ofertado por ninguna agencia española. En definitiva, se trata de un término que ha surgido ligado al componente cultural del clima frío de Alemania.

Futhark 6 (2011)

Martínez, Internet como herramienta,

163-192

ISSN 1886-9300 


\begin{tabular}{|l|l|}
\hline Wellnessreise & $\begin{array}{l}\text { vacaciones en un spa } \\
\text { www.mein-wellnessurlaub.de/ }\end{array}$ \\
$\begin{array}{l}1 . \quad \text { Spa \& Wellness en Gran Canaria - } \\
\text { vacaciones de descanso y recreacion } \\
\text { vacaciones de salud y bienestar. Gran } \\
\text { Canaria te ofrece una multitud de centros de } \\
\text { spa y wellness }{ }^{33} \text { en los que encontrarás los } \\
\text { últimos tratamientos y las más } \\
\text { www.isla-canaria }\end{array}$ \\
\hline Weltraumtourismus & $\begin{array}{l}\text { turismo espacial / turismo en el espacio } \\
\text { Weltreise } \\
\text { mundo alrededor del mundo / vuelta al } \\
1 . \quad \text { Viajes Vuelta al Mundo } \\
\text { www.viajesterral.com } \\
\text { VUELTAS AL MUNDO: Ruta Capitán Cook. } \\
\text { Sigue los pasos del Gran Navegante 25 días } \\
\text { /23 noches. Precio: } 5.790 € \text { tasas incl. }\end{array}$ \\
\hline
\end{tabular}

\section{Conclusiones}

Hemos insistido en varias ocasiones que el turismo y, en concreto, los productos turísticos están muy vinculados a las modas y a las tendencias que, a su vez, vienen determinadas por la aparición de nuevos destinos turísticos y/o con motivo de eventos culturales, deportivos o sociales. Muchas nuevas denominaciones aparecen de la misma forma que desaparecen, incluso lo hacen sin dejar huella en los diccionarios. Como decía P. Newmark "En realidad los neologismos no se pueden cuantificar con exactitud, ya que muchos oscilan entre la aceptación y el olvido y otros tantos son creaciones individuales de breve duración" 34 Por esta razón, la bibliografía impresa que existe al

33 También en español aparece la palabra Wellness que significa "bienestar". Con ella se hace referencia a los balnearios, sólo que este término ha quedado algo más anticuado y se relaciona con los baños terapéuticos. El extranjerismo es un término más comercial que la traducción

34 Ibid. NeWMARK, P.,(1958). Pág. 193

Futhark 6 (2011)

Martínez, Internet como herramienta,

$163-192$

ISSN 1886-9300 
respecto es muy escasa, motivo por el que el traductor tiene tantas dificultades a la hora de traducir algunos productos turísticos.

Esta laguna se acentúa aún más si hay que encontrar equivalencias entre el alemán y el español. Para traducir algunos conceptos hemos tenido que recurrir al inglés como lengua puente, ya que, por un lado, el inglés está muy presente en el tecnolecto turístico y, por otro lado, porque hay más diccionarios de inglés-español y de alemán-inglés que diccionarios de alemán-español que recogen esta terminología. Ni si quiera algunos diccionarios electrónicos de nueva creación son capaces de hacerse con la gran pluralidad de términos o neologismos ad hoc. Por esta razón, las mismas agencias de viaje han sido la fuente de información más inmediata. Salvo algunas excepciones, nuestro procedimiento de trabajo ha consistido en hacer una traducción casi literal de una palabra compuesta en alemán y luego la hemos buscado en las agencias de viajes en español, tal cual la hemos traducido, para ver si está recogida en la red. Si los conceptos aparecían registrados por algunas agencias de viaje, entonces han sido tomados como referencia.

El resultado ha sido muy satisfactorio pues hemos encontrado una traducción apropiada para cada término con la excepción de algunos de ellos: Kaffeefahrt, Butterfahrt y Tour Überwinterung. Para éste último hemos ofrecido una traducción literal "tour de hibernación" aunque no se recoge como tal en ningún catálogo de las agencias de viaje españolas. Como aludíamos al principio no sólo se trata de hallar una equivalencia entre significantes sino que también es preciso tener en cuenta el componente cultural. De este modo, éste será un producto turístico que se oferte en lugares con un clima desapacible y de ahí se entiende que no exista como concepto donde el clima es muy agradable como en España.

Aunque el producto Kaffeefahrt lo hemos identificado con un tipo de viaje dentro del "turismo promocional" no hemos podido definirlo como "viaje de ...".

Concretamente la denominación Butterfahrt viene determinada por unas circunstancias espacio-temporales muy precisas. Sin embargo, este término se ha seguido utilizando para aquellos viajes hacia otras zonas donde los productos son más baratos o sobre los que no hay que pagar impuestos. Una equivalencia apropiada podría ser "viajes duty 
free" pero aún así hemos revisado varios catálogos de distintas agencias de viaje en internet y no lo hemos encontrado registrado como oferta.

Del mismo modo, al no existir un consenso en lo que a denominación se refiere, también se da el caso en el que aparecen dos términos que hacen alusión a una misma realidad como ocurre con Pilgerreise y Wallfahrt. Otras denominaciones como Studienreise, Bildungsreise, Sprachreise e incluso Forschungsreise se solapan por el motivo de viaje que comparten, esto es, todos estos términos contienen un sema en común como es el "estudio".

La cantidad de conceptos que puede llegar a producirse es mucho mayor que la que aquí se presenta; podría decirse que los productos serían infinitos partiendo siempre del motivo del viaje. La lengua española tiende cada vez más a especificar el tipo de viajes aunque la forma en la que lo hace dista mucho de cómo lo resuelve la lengua alemana. Existe una clara diferencia entre el alemán y el español a la hora de introducir neologismos. Hemos observado que el alemán, como lengua más sintética que el español en la creación de su léxico, tiende a crear nuevos compuestos que definen con precisión el tipo de viaje. Por el contrario el español, más analítico que el alemán, opta por estructuras compuestas por un sustantivo, un enlace o preposición y otro sustantivo (viaje en tren, viaje para la Tercera Edad, etc.) o por un sustantivo y un adjetivo (turismo cultural, viaje individual).

De las cuatro combinaciones posibles para formar los compuestos, esto es, con -fahrt, -urlaub, -ferien y -reise, sabemos que la extensión "reise" 35 se reserva para aquellos términos relacionados con los medios de transporte como Auto-,Bahn-, Bus-, Flugs-. Asimismo, toman esta extensión aquellos viajes denominados con un sustantivo acabado -ung y que definen una actividad, como por ejemplo Bildungsreise $y$ Forschungsreise. También aparecen con esta terminación aquellos viajes que contienen una indicación local, tales como Rundreise, Fernreise, Blaue Reise o Weltreise. Sobre las demás extensiones se desconoce el motivo de su uso para la formación de palabras.

\footnotetext{
${ }^{35}$ Según Das digitale Wörterbuch der deutschen Sprache des 20. Jh. en http://www.dwds.de/woerterbuch

Futhark 6 (2011)

Martínez, Internet como herramienta,
}

163-192

ISSN 1886-9300 
La presencia de extranjerismos procedentes del inglés generalmente es más acusada en el alemán que en el español. En este estudio también en español se prefiere el calco semántico al extranjerismo ${ }^{36}$ como se observa en el par Heliskiing (alemán) y Heliesquí (español). Sin embargo, también hemos visto que algunos extranjerismos que conviven con su traducción como Trekking y senderismo o wellness y viajes de bienestar.

Para terminar con este artículo y, haciendo eco de las palabras de Newmark, quien estima que no debemos crear neologismos a no ser que "tengan autoridad o lo hagan con morfemas grecolatinos fácilmente inteligibles", queremos dejar constancia de que nuestro objetivo no ha sido crear neologismos sino investigar en la red para localizar aquellas palabras de nueva creación que ya existen en el uso de la lengua española, independientemente de que estén recogidas en diccionarios, y que son equivalentes a las palabras alemanas.

\section{REFERENCIAS BIBLIOGRÁFICAS}

Alcaraz, E. y Martínez, Ma A., Diccionario de lingüística moderna. Barcelona: Ariel, 2004 (2. ${ }^{a}$ ed.)

AlVAR, M., "Los diccionarios académicos y el problema de los neologismos", en El neologismo necesario, Fundación EFE, Madrid, 1992. Págs. 51-70.

ÁlvareZ JURADO, Manuela; BALBUENA TOREZANO, M. del Carmen, "El léxico turístico en la red (alemán-francés-español): análisis terminológico orientado a la traducción". En: Borrueco Rosa, María A. (Dir.), El léxico Turístico. Colección Estudios Lingüísticos y Turismo. Sevilla: Junta de Andalucía, Consejería de Turismo, Comercio y Deportes, 2009

Bugnot, MARIA-Agne, Tesis Doctoral. Texto Turístico y Traducción especializada. Estudio crítico de un corpus español-francés sobre la Costa del Sol (1960 2004) en MA Bugnot - dialnet.unirioja.es

${ }^{36}$ Cfr. CALVI, M. V., "Notas sobre la adopción de anglicismos en español y en italiano", Lingüística Española Actual, XX, no1, 1998. Págs. 29-39. 
CALVI, M. V. "Notas sobre la adopción de anglicismos en español y en italiano", Lingüística Española Actual, XX, no 1, 1998, págs. 29-39.

Calvi, Ma Vittoria, El léxico del turismo (en http://www.ub.es/filhis/culturele/turismo.html

COSERIU, Eugenio: La formación de palabras desde el punto de vista del contenido, Gredos, Madrid, 1978.

Das digitale Wörterbuch der deutschen Sprache des 20. Jh. en http://www.dwds.de/woerterbuch

ELENA GARCÍA, P., Aspectos teóricos y prácticos de la traducción alemánespañol, (1 ${ }^{\text {r }}$ reimp.), Ediciones Universidad Salamanca, Salamanca, 1990.

GARcíA YEBRA, V., Teoría y práctica de la traducción, Gredos, Madrid, 1982.

GRADDOL, DAVID (1997). The future of English? A guide to forecasting the popularity of the English language in the 21st century. London: British Council. Available for free from the website of the British Council [1]. en http://www.britishcouncil.org/learning-eltfuture.pdf

Guerrero Ramos, G. Neologismos en el español actual, Madrid, Arco Libros, 1995

LANG, M., Formación de palabras en español, Cátedra, Madrid. 1990.

MARTÍNEZ, P: "La estructura temática en la traducción: El caso de los textos turísticos", Livius, 12, 1998. Págs. 107-120.

Máster Universitario en Traducción de textos con fines específicos, Interpretación y Doblaje de las lenguas española y alemana traducción al castellano de textos Biosanitarios, págs. 10 - 11.

NeWMARK, P. Manual de traducción. Madrid: Cátedra, 1992.

Gallego, J. F. y Peyrolón Melendo, R., Diccionario de Hostelería. Hotelería y turismo. Restaurante y gastronomía.Cafetería y bar. Madrid, Parninfo, 2004 
Orte Bermúdez, J. M., Conocimientos sobre el mundo del turismo, Lleida, Editorial Milenio

VinAY \& DARBELNET, Stylistique comparée du français et de l'anglais. Méthode de traduction, Didier, Paris,1958.. 1997

Páginas web. Todas ellas consultadas por última vez el día 29 de julio de 2010

http://www.cervantesvirtual.com/escaparate/neologismos.jsp

http://cvc.cervantes.es/obref/aeter/conferencias/garcia.htm

http://www.uni-protokolle.de/Lexikon/\%DCbersicht_Tourismus.html

http://www.ine.es/.

http://www.pasonoroeste.com/

www.tuaregviatges.es/

http://latercera.com/contenido/730 2384359.

http://www.cordoba.abc.es/hemeroteca/resultados/etilico.html

http://dict.leo.org

www. vacacionesenlaplaya

http://dix.osola.com/index.php

www.capitannemo.com.ar/que\%20es\%20un\%20viaje\%20educativo.ht

$\underline{\mathrm{m}}$

http://www.isyayachting.com/es/

www. elpais.com/articulo/.../Club/Vacaciones/...13/Tes -

www.huumeboikotti.org/es/turismo.html

http://www.boletin-

turistico.com/diccionario.html?task=list\&glossid=1\&letter=E\&page=6

http://www.trekkingyaventura.com/expediciones/index.htm

http://viajar.euroresidentes.com/2008/08/vacaciones-para-ciclistas-en-

europa.html

www.erlebnisreisen-weltweit.de/.../fernreisen.php

http://www.crucerosfluviales.es/

www.uca.es/web/organizacion/.../fondos_bib_6 -

http://rutasmagicas.es/viajes-para-mujeres-1/

http://www.hotelbienestar.com/es-es/mujeres-solas.htm

http://www.termcat.cat/dicci/hivern/index.html

Futhark 6 (2011)

Martínez, Internet como herramienta,

$163-192$

ISSN 1886-9300 
http://en.wikipedia.org

http://conjuge.blogspot.com/2010/01/

http://www.viajesybilletesdeavión.es/online-viajes-para-jovenes-html

http://www.viajeshobby.com/quienes somos.htm

http://www.bebesymas.com/noticias/babyviajes-agencia-de-viajes-para-

ninos

www.largaestancia

www.educared.net/.../hemero/.../naturismo

http://dict.leo.org

http://www.turismoyperegrinaciones.com

www.vacaciones-a-caballo.com/

http://destinia.com/viajes/Circuito-por-Alemania---Viajes-Alemania

http://dict.leo.org

http://locuraviajes.com/blog/viajar-en-barco-consejos/

www.tercera-edad.org/.../vacaciones-imserso.asp

http://www.viajarsolo.com/

http://www.esports10.com/esp/index.php

www.viajeshobby.com

http://www.ef.com/info/es/viajes-de-idiomas.html?tr=HQ\&tc=HQ

http://www.viajesyturistas.com/turismo-urbano-en-europa

ww. viajaysurfea.com/

www.surfdestiny.com

www.orquideatours.com/specialtours

www.viajesiberia.com/.../subhomeBuceo.aspx

http://www.poraqui.net/diccionario/index.php/term/Glosario+de+turismo+ y+hosteler\%C3\%ADa,trekking.xhtml

www.turingactiva.com

www.mein-wellnessurlaub.de/

www.isla-canaria

www.viajesterral.com 